\title{
Mine Ventilation System Variable Resistance Regulate Air Quantity Economy and Its Impacts on Artisanal Mine in Ivory Coast
}

\author{
Kouame Arthur Joseph Kouame, Fuxing Jiang, Yu Feng and Sitao Zhu \\ School of Civil and Environmental Engineering, University of Science and Technology Beijing, 30 Xueyuan Road, Haidian District, Beijing \\ 100083, PR China
}

\begin{abstract}
The artisanal gold mining is one of the major illegal activities in Ivory Coast. Thousands of indigents and foreigners including men, women and children are involved in this dangerous activity. Contracting contagious diseases such as HIV/AIDS and multiple lung diseases are commonplace on the artisanal mining sites due to air pollution. For this reason, the differential analysis, research mine ventilation system by changing the working windage adjustment for air flow of the economy, identifies factors, obtained discriminant variable resistance air volume control economic quantitative criteria for underground actual situation of joint variable resistance method and economic variable resistance than the concept of the development of effective mine ventilation system to improve air quantity adjusting rheostat economical way. The findings of this study can help lead to better safety practices in mining in order to improve the health and safety of the miners who are involved in artisanal mining activities in Ivory Coast and other mining sites over the world.
\end{abstract}

\section{Introduction}

\subsection{Definition}

According to the definition, artisanal and small-scale mining refers widely to miners using inadequate technical materials to run mines. Due to advancement in technology nowadays, some small miners no longer use artisanal methods, and they run huge operations ([1], [2]). In order to depict small, medium, large, and informal mining activities which are mostly run by illegal miners who carried out mining with low technology or minimal machinery, it is common to use the term artisanal mining [3]. Over 100 million people around the world, mainly in developing counties, rely on this sector for income. Ivory Coast is a country in West Africa with an annual gold production that rose from 10 tons in 2014 to 23.5 tons in 2015. The artisanal mining mainly refers to mining operated by individuals, groups or communities (foreigners and indigenes) illegally due to fact that illegal miners mostly don't acquire legal status. The active involvement of many people in artisanal mining activities in Ivory Coast is mainly due to the high rate of abject poverty and the low price of agricultural produce. In order to deal with poverty and better their lives, the people engage in artisanal mining in all the parts of the country. Even when the artisanal mining sector has harmful side effects (environmental, social and financial challenges) that undermine the country's development, it has the potential to contribute to the development of the state through the provision of employment, increase of local purchasing power, stimulation of local economic growth and slowing of urban migration.

At present, for mine ventilation, air volume control studies focus mainly on the stability of the ventilation system ([4], [6], [7]) with little research on mine ventilation system and air volume control economy, which makes it difficult to judge mine ventilation system and air volume control economy. In this paper, we study mine ventilation system and air volume control to determine the impact of factors that determine air quality and to identify quantitative conditions so as to formulate reasonable measures to improve mine ventilation system and air volume control rheostat economy for efficient production and safety of coal mines and gold mines. Adopting an effective mine ventilation system is of critical benefit to Ivory Coast. Utilizing natural or mechanical air pressure, the mine ventilation system is designed to provide fresh air as well as expel foul air. And with more people getting involved in mining activies in Ivory Coast, underground mining is inevitable in the coming 10 years. There are many differences between open pit mining and underground mining. When the mining depth increases, the temperature becomes higher than the surface ground and will increase as it gets deeper. Aditionally, mining activities always generate hazardous gases and dusts-diesel emissions, blasting fumes, radiation, dusts, battery emissions, and many other contaminants - which are harmful to the workers and will cause some occupational diseases, such as silicosis, or even worse. The following is the main components of surface ground air (Table I). 
Table 1. Main components of surface ground air.

\begin{tabular}{|c|c|c|}
\hline Conponent & $\begin{array}{c}\text { Mass } \\
\text { concentration / \% }\end{array}$ & $\begin{array}{c}\text { Bulk } \\
\text { concentration / \% }\end{array}$ \\
\hline Oxygen $\left(\mathrm{O}_{2}\right)$ & 23.17 & 20.90 \\
\hline Nitrogen $\left(\mathrm{N}_{2}\right)$ & 75.55 & 78.13 \\
\hline $\begin{array}{c}\text { Carbon } \\
\text { dioxide }\left(\mathrm{CO}_{2}\right)\end{array}$ & 0.05 & 0.03 \\
\hline Rare gases & 1.23 & 0.94 \\
\hline
\end{tabular}

Once the air comes into mining shafts, both its compoents and properties will change, the concentration of oxygen decreases while the concentration of carbon dioxide increases; various toxic gases and dusts mix and there is change in the air temperature, moisture and pressure. Besides $\mathrm{O}_{2}, \mathrm{~N}_{2}, \mathrm{CO}_{2}$ and water vapour, the main components of the underground mining air are $\mathrm{CH}_{4}, \mathrm{CO}$, $\mathrm{H}_{2} \mathrm{~S}, \mathrm{SO}_{2}, \mathrm{NO}_{2}, \mathrm{NH}_{3}, \mathrm{H}_{2}$ and dusts, with $\mathrm{CO}, \mathrm{H}_{2} \mathrm{~S}, \mathrm{SO}_{2}$ with $\mathrm{NO}_{2}$ being the most harmful component. Thus, underground mining would not be possible without a ventilation system.

In underground mining, air is necessary not only for breathing but also to disperse chemical and physical contaminants (gases, dusts, heat, and humidity). Ventilation is the control of air movement, its amount, and direction. It is sometimes described as the lifeblood of a mine, the intake airways being arteries that carry oxygen to the working areas and the returns veins that conduct pollutants away to be expelled to the outside atmosphere. Without an effective ventilation system, no underground facility that requires personnel to enter it can opreate safely. Literature[7], [4] shows that an effective mine ventilation system possesses such assets as follows: dilution and expulsion of $80 \%-90 \%$ of the hazardous gas, reduction of $70 \%-80 \%$ of the fine particles and ousting of $60 \%-70 \%$ of the heat of the working faces. These merits offer protections for the mining activities and also some suggestions as to postmedical checks, training, strategy of controlling dust, dust masks wearing, and monitoring of gas in order to decrease the working incidents. Indeed, it can also improve the miners' working productivity at a lower cost.

\subsection{Ventilation mining in China}

China's research for ventilation system started with the establishment of the Peoples Republic of China. Since the 1950 s, researches in mine ventilation theory and technology have achieved some major breakthroughs including the following:

(1) Extensive research and measurement on the roadway ventilation resistance;

(2) The establishment of a variety of work surface turbulence equations and mass transfer analysis of pollutant concentration calculation method, which provides a theoretical basis for the method of calculation of the amount of wind;

(3) application of computer calculation and analysis of complex ventilation network, which provides an effective method of analysising mine ventilation system;
(4) developed Jet Ventilation techniques and the applications to use wind flow pressure to regulate and direct airflow control technology

(5) deepening the research of unsteady flow law in the case of mine fire, establishment of a number of typical wind flow control program.

\section{A mine ventilation system air volume control rheostat factors affecting economy}

\subsection{Qualitative analysis}

In coal mines, ventilation systems for air volume often due to the mining face of change and transfer of gas emission and other natural conditions change and change the fan performance changes itself. In order to ensure the availability of air in the mine, there is need for timely supply of air volume control. Variable resistance, which includes the economic benefits of air-flow method are constrained mainly by two factors. First, to meet the demand for air volume after the economic gains which the scale of production mainly determines. The second is to change the drag caused by the additional energy consumption and cost of the project. The energy consumption is mainly used for ventilation ductwork to overcome resistance and maintain air flow stability. The law of resistance shows that only the air flow and pressure drag on.

In summary, the impact of the mine ventilation system air volume control rheostat law economic factors includes wind, drag, engineering and production scale.

\subsection{Branch changes on the economic impact of wind resistance}

In the mine ventilation system management process, air volume changes at the mining area producing a continuous change. When the wind through the natural points cannot meet the need, it often used to change the drag method to regulate air flow to meet mine's demand for wind. Most of our coal mining uses wings; each wing has a separate return air tunnel, the implementation of partition is airy and the simultaneous production of multiple mining areas, each with a down hole location constitutes a complex wind parallel networks. To facilitate the analysis, the mine ventilation network simplification of Fig. 1 consists of three parts:

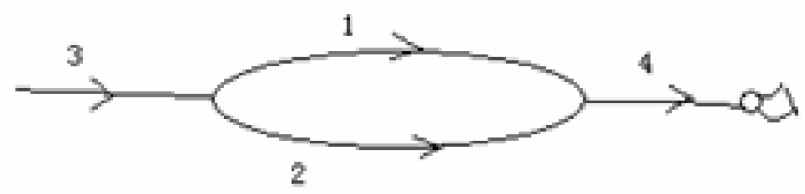

Figure 1. Simplified ventilation network graph

Mine's total inlet branch 3, equivalent drag r3, mine's total return air branch 4 , equivalent drag $\mathrm{r} 4$, mine segment with the wind segment branch 1, 2, the equivalent wind resistance $\mathrm{r} 1, \mathrm{r} 2$. The need to increase the air flow branch for the branch including a large air 
volume $\mathrm{r} 1$, including the other branches of the equivalent branch $\mathrm{r} 2$.

Where $\mathrm{r} 1, \mathrm{r} 2$ respectively Mine Main Fan constitute two independent circuits.

\subsubsection{The increasing resistance adjustment}

To increase resistance to increased air volume regulator, that is, greater wind resistance of the branch, a large amount of air is required to increase the air volume branching approach because of mine total drag.

$$
R=r_{0}+\frac{1}{\left(\frac{1}{\sqrt{r_{1}}}+\frac{1}{\sqrt{r_{2}}}\right)^{2}}
$$

where $r_{0}=r_{3}+r_{4}$; When the drag r1 Changes; r1 differential on both sides,

Available $d R=K_{1} d r_{1}$ (1-1); Where

$$
K_{1}=\frac{1}{r_{1} \sqrt{r}_{1}\left(\frac{1}{\sqrt{r_{1}}}+\frac{1}{\sqrt{r_{2}}}\right)^{3}}
$$

Seen, when the drag increases, the total drag increases.

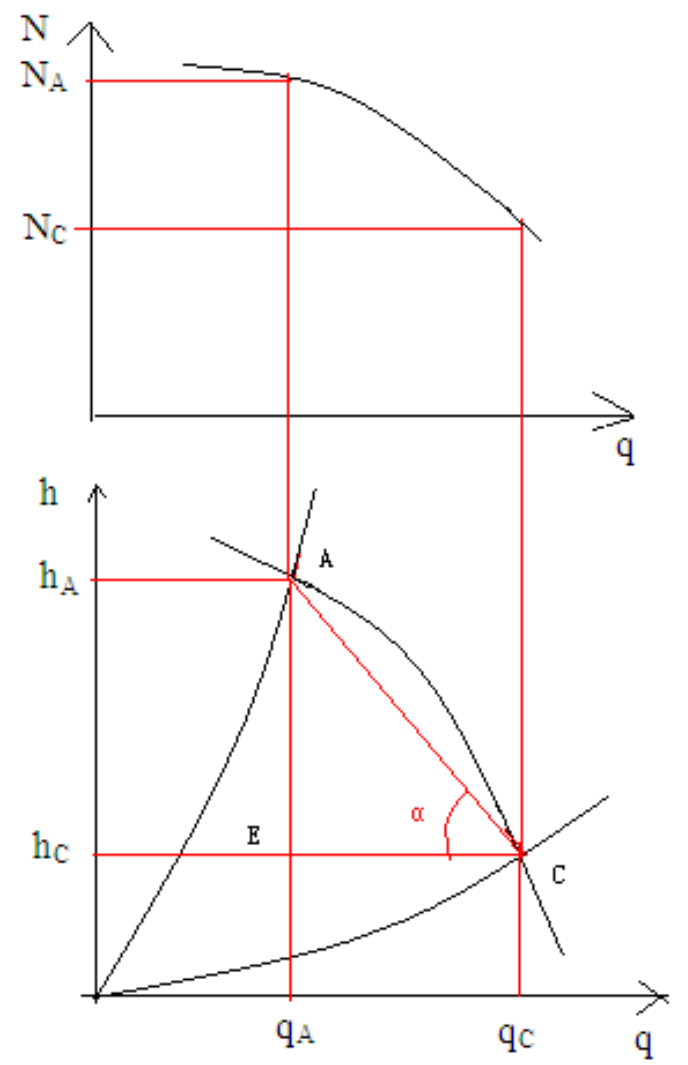

Figure 2. Mine Ventilation Resistance, main fan performance curve

Shown in Fig. 2; Let $\overline{C E}$ and $\overline{C A}$ connection angle $\alpha$, the $\triangle A E C$ in the infinitesimal, $\tan \alpha=\frac{\overline{E A}}{\overline{C E}} \quad ; \quad \overline{A E}=d h_{f} \quad, \quad \overline{C E}=-d q_{f} \quad, \quad$ So $d h_{f}=-\tan \alpha d q_{f} \quad, \quad$ (1-2); Where, $q_{f}, h_{f}$, respectively for the main mine fan air flow and air pressure.

Law by the wind pressure $h_{f}=R q_{f}{ }^{2}$; Differentiations $d h_{f}=2 R q_{f} d q_{f}+q_{f}{ }^{2} d R$ (1-3)

Parallel pressure ventilation network according to law $h_{1}=h_{2}$

Obtain $r_{1}\left(q_{0}-q_{2}\right)^{2}=r_{2} q_{2}^{2} ;$ its differentiations $d q_{2}=K_{2} d q_{0}+K_{3} d r_{1}(\mathbf{1 - 4})$

$$
K_{2}=\frac{1}{\sqrt{\frac{r_{2}}{r_{1}}+1}}, K_{3}=\frac{q_{0} \sqrt{\frac{r_{2}}{r_{1}}}}{2 r_{1}\left(\sqrt{\frac{r_{2}}{r_{1}}}+1\right)^{2}}
$$

where $q_{0}$ is the inlet and return air branch Airflow, Size equal to $q_{f}, h_{1}, h_{2}$ respectively of the branch 1,2 pressure , $q_{1}, q_{2}$ respectively, the air flow rate for the branch 1,2 .

Obtained by the above equations can be derived

$$
\begin{gathered}
d q_{0}=-X_{1} K_{1} d r_{1},(1-5) \\
d q_{2}=\left(K_{3}-X_{1} K_{1} K_{2}\right) d r_{1},(1-6) \\
d h_{f}=\tan \alpha X_{1} K_{1} d r_{1},(1-7)
\end{gathered}
$$$$
\text { where, } \quad X_{1}=\frac{q_{0}^{2}}{2 R q_{0}+\tan \alpha}
$$

When $r_{1}$ increases, by the (1-5) shows that the total amount of wind $q_{0}$ mine be reduced,

By 1-6 combined, the actual situation shows, $K_{3}-X_{1} K_{1} K_{2}>0$, So branch 2 air volume increases $q_{2}, 1-7$ shows that it is the work of the main fan pressure $h_{f}$ increases.

Meanwhile, the 1-1 shows that, when there is increase, the main fan operating point changes.

Shown in Fig. 2, the operating point changes from point $\mathrm{C}$ to point $\mathrm{A}$, resulting from the total air volume $q_{C}$ mine decreased to $q_{A}$, the ventilation resistance increases from the point $h_{C}$ to $h_{A}$, increasing the fan power set by $N_{C} N_{A}$.

Increasing resistance in the regulation for the centrifugal fan can increase the wind tunnel gate 
resistance (to reduce its opening) [5]. This method is relatively simple and implementation cost of the project is small and suitable for the production of smaller mines. However, from the above analysis, this approach will bring additional energy consumption, affecting the total air volume ventilation system stability. So adjust the time not too long.

\subsubsection{The reduction in resistance adjustment}

Reduction in resistance adjustment that reduces total intake, return air branch drag, increasing the total amount of wind to increase the air volume requires a larger air volume branch in two ways.

When the drag $r_{0}$ changes, the

$$
R=r_{0}+\frac{1}{\left(\frac{1}{\sqrt{r_{1}}}+\frac{1}{\sqrt{r_{2}}}\right)^{2}}
$$

$r_{0}$ Differential on both sides, we get $d R=d r_{0}$

Seen, when the drag A1 is reduced, the total drag decreases.

And then the $r_{1}\left(q_{0}-q_{2}\right)^{2}=r_{2} q_{2}{ }^{2}$ Differentiations $d q_{2}=\frac{d q_{0}}{1+\sqrt{\frac{r_{2}}{r_{1}}}} ;(1-9)$

From $(1-2)(1-3)(1-8)(1-9)$ were derived restaurants $d q_{0}=-X_{1} d r_{0}(1-10)$

$$
\begin{gathered}
d q_{2}=\frac{-X_{1} d r_{0}}{1+\sqrt{\frac{r_{2}}{r_{1}}}} \\
d N=\tan \alpha X_{1} d r_{0}
\end{gathered}
$$

When $r_{0}$ is increased by $1-10$, it shows that the total amount of wind $q_{0}$ mine increased by 1-11 and shows that two branches of the increased air flow $q_{2}$ also by (112) shows that the main fan working pressure decreases.

Meanwhile, 1-8 shows that when $r_{0}$ decreases, $\mathrm{R}$ decreases, making the main fan operating point to change. Shown in Fig. 2, the operating point changes from point A to point $\mathrm{C}$, resulting in the total air volume from the mine increased to $q_{A} q_{C}$; the ventilation resistance is reduced to the $h_{A} h_{C}$; fan power is reduced to the $N_{A}$ $N_{C}$.

The reduction in resistance regulation in general is in the mine (or system) of the main inlet and return air duct taken to increase in parallel roadway, reduce air duct, wide brush roadway, replacement of the friction coefficient smaller shoring, and other measures to reduce local resistance ([5], [6]). From the above analysis, this approach allows the main fan running costs of the economy, but the cost of the project is large, suitable only for large-scale production of the mine.

\section{Mine ventilation system for air volume adjustment rheostat economic analysis}

\subsection{Mine ventilation system air volume control rheostat definition of economics}

When the ventilation network sees a drag strip $r_{i}$ change in wind direction, assuming drag increment is $d r_{i}$, the resulting change in the total amount of drag is $d R$, then its total economic benefits the mine ventilation system $M$ impact $\psi_{i}$ can be expressed as $d r_{i} \propto \psi_{i}(i=1,2,3, \ldots, n), \psi_{i}$ is the mine ventilation system for air volume adjustment rheostat revenue degree, the size of the reaction of the drag is changed economic growth, namely economy. Set up

Where in $d M \mathrm{D}$ is the change in the network has the $\operatorname{drag} d r_{i}$, when the mine ventilation system changes in the value of total economic benefits. $\psi_{i}$ is larger, indicating that the variable resistance regulates air flow economy better.

\subsection{Economic introduction of variable resistance than $\lambda_{e}$}

By the previous analysis, adjusting for changing the working speed air flow method, increasing resistance adjustment and reduction in resistance regulation has advantages and disadvantages. To resolve this contradiction in the actual production, two methods can be applied: Reduce intake, return air branch drag, increased need to wind fewer branches drag, which combined increased need to wind a large branch of the air flow in order to meet production requirements [8 ]. The method of this regulation is defined as the amount of wind resistance combined variable air volume control method, increasing resistance and resistance reduction ratio known as the Joint variable resistance ratio.

Joint variable resistance method model shown in Figure 1-1, $r_{3}$ and $r_{4}$ required a reduction in the total resistance of the mine into the return air branch $\left(r_{0}=r_{3}+r_{4}\right), r_{2}$. Thus there is the need to increase the amount of wind branch, $r_{1}$ including the need to increase resistance to other branches, including branches equivalent branch. Wherein $r_{1}, r_{2}$ and $r_{0}$, respectively, and the main mine fan constitute two independent loops. 


$$
\psi_{i}=\frac{d M}{|d R|}
$$

Mine Main Fan constitutes two independent loops, and meets $\Delta r_{0}=-\lambda \Delta r_{1}$. Wherein $\Delta r_{0}, \quad \Delta r_{1}$ of the branch into the return air drag and wind resistance change amount Branch 1.

When $\lambda$ met $\psi_{i}=\frac{d M}{|d R|} \rightarrow \max$, economics highest point of $\lambda$ is defined as the economic variable resistance ratio, denoted by $\lambda_{e}$.

Insufficient air flow ventilation system can easily lead to accumulation of gas, causing suffocation and explosion, ventilation and safety effects and the indirect effects of mine efficiency. The mine ventilation network should be to ensure the mine ventilation system airflow stability [4], under the premise to maximize economy.

\subsection{Mine ventilation system joint economic analysis rheostats}

Joint variable resistance model for economic analysis, design total intake, return air drag $r_{0}$ and $r_{1}$, respectively, a branch change $\Delta r_{0}, \Delta r_{1}$ and $\Delta r_{0}=-\lambda \Delta r_{1}$, the total drag variation $\Delta R$, the increase in total revenue for the $\Delta M$. Settlement revenue per unit time is as shown in Table 2-1.

Table 2-1 Rheostat adjusted income statement

\begin{tabular}{|c|c|c|c|}
\hline Branch & 1 & 2 & 3.4 \\
\hline $\begin{array}{l}\text { Air volume to meet } \\
\text { revenue ten thousand } \\
\text { Yuan A } 10,000 \text { yuan } \\
\backslash \mathrm{m}^{3}\end{array}$ & 0 & $A \Delta q_{2}$ & 0 \\
\hline $\begin{array}{l}\text { Increase power } \\
\text { consumption } \\
B \quad 10,000 \text { yuan } \backslash k w\end{array}$ & $B \Delta N_{1}$ & 0 & $B \Delta N_{0}$ \\
\hline $\begin{array}{l}\text { Power consumption } \\
\text { to maintain stable air } \\
\text { flow C10,000 yuan } \\
\backslash m^{3} \quad\left(\Delta q_{0} \geq 0 \text { h }\right. \\
C=0\end{array}$ & 0 & 0 & $C \Delta q_{0}$ \\
\hline $\begin{array}{l}\text { Engineering } \\
\text { cost } D 10,000 \text { yuan }\end{array}$ & 0 & 0 & $D r_{0}$ \\
\hline$\Delta M$ & \multicolumn{3}{|c|}{$A \Delta q_{2}+B \Delta N+C \Delta q_{0}+D r_{0}$} \\
\hline
\end{tabular}

where, $\Delta N_{1}$ and $\Delta N_{0}$ are the branches 1 and 3 (or 4 ) drag to change the main cause of the mine ventilation system fan power variation, $\Delta N=\Delta N_{0}+\Delta N_{1}$

From the previous analysis, the mine ventilation system to change the working method windage adjustable air volume gains and $r_{0}, r_{1}$ branch related to changes in wind resistance, assuming that only the operating point is changed, the characteristic curve did not change. To this end, the mold showed in united rheostat.

Type variable resistance caused due to economic analysis of the changes.

Let branches 1 and into the back, the wind drag each branch change $\Delta r_{1}, \Delta r_{0}$; Parallel networks mine total differential of total drag $d R=d r_{0}+K_{1} d r_{1}(2-2)$

According to the law $h_{1}=h_{2}$ parallel pressure ventilation network was $r_{1}\left(q_{0}-q_{2}\right)^{2}=r_{2} q_{2}^{2}$,

Therefore $d q_{2}=K_{2} d q_{0}+K_{3} d r_{1}, \quad$ (2-3)

All kinds can be derived from the above $d N=h_{f} d q_{f}+q_{f} d h_{f}$

By the (1-4) know; can be obtained from Table 2-1; $\mathrm{dM}=\mathrm{Adq}_{2}+\mathrm{BdN}+\mathrm{Cdq}_{0}+\mathrm{Dr}_{0}(2-4)$

Set up $d r_{0}=-\lambda d r_{1}$,

$\lim \frac{d M}{|d R|}= \begin{cases}\frac{\left(A K_{2} X_{1}-C X_{1}-D\right) \lambda+A\left(K_{3}-K_{1} K_{2} X_{1}\right)-B\left(1-K_{1}\right) K_{4}-C X_{1} K_{1}}{\lambda-K_{1}}, & 0 \leq \lambda<K_{1} \\ \frac{\left(A K_{2} X_{1}-C X_{1}-D\right) \lambda+A\left(K_{3}-K_{1} K_{2} X_{1}\right)-B\left(1-K_{1}\right) K_{4}-C X_{1} K_{1}}{K_{1}-\lambda}, & K_{1}<\lambda\end{cases}$

Among $K_{4}=\frac{\tan \alpha}{2 R q_{0}+\tan \alpha}$

The above analysis shows that when $\lim \frac{d M}{|d R|} \rightarrow \max$ is full, from the economic point of view, the system shows the most reasonable proportion of variable resistance adjustment. From (2-5), when the characteristic curve is not changed, $\tan \alpha$ are constant, economy $\psi_{i}$ and $\lambda$, only the scale of production, and therefore according to the different production scale, drawing the $\psi_{i}-\lambda$ curve.

The analysis shows that when the mine production is smaller, it allows $\frac{A}{D}<\frac{K_{1}}{K_{3}}$

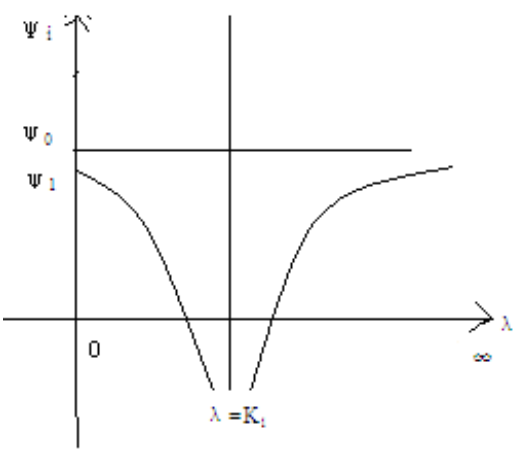

Figure 3. Small-scale mine air volume control rheostat economy curve

Smaller yield, $\psi_{j}-\lambda$ curve as shown in Fig. 3 . When $\lambda=0$ is, that only the method of increasing resistance adjustment, has a relatively high economic, 


$$
\psi_{i}=\frac{A\left(K_{3}-K_{1} K_{2} X_{1}\right)-B\left(1-K_{1}\right) K_{4}-C X_{1} K_{1}}{K_{1}}
$$

There is no visible problem engineering expenses, mainly due to the additional energy consumption and output and total air volume changes, so adjust the time not too long, otherwise too much additional energy consumption, impacts the economy. When $\lambda \rightarrow \infty$, that resistance reduction method using only regulate $\psi_{i}=A K_{2} X_{1}-D$, there is no additional visible decline in wind energy issues, due to smaller production, so the cost of the project is a major constraint on economic factors. Although the reduction in resistance of the main fan running costs the economy, but construction costs are too high and the economy with respect to increasing resistance method improves, but the magnitude is not large, so the production of smaller mines by reduction in resistance adjustment method is not practical.

When $0<\lambda<\infty$, that combined variable resistance adjustment $\lambda$ increases, $\psi_{i}$ decreases and then increases, but is always less than the economic adjustment, reduction in resistance is low, when combined variable resistance ratio $\lambda=K_{1}$, the mine changes in the value of total drag $\Delta R \rightarrow 0$, drag curve indicated by the mine, no additional energy consumption, air flow stability [1], the existing scale of production, the reduction in resistance larger proportion of project costs, up from Fig. 1-4, shows that at this time the most economical poor. Visible production scale is small, the increasing resistance of the best economic regulation. At such production conditions, the reduction in resistance regulation or co-resistance reduction method is not advantageous.

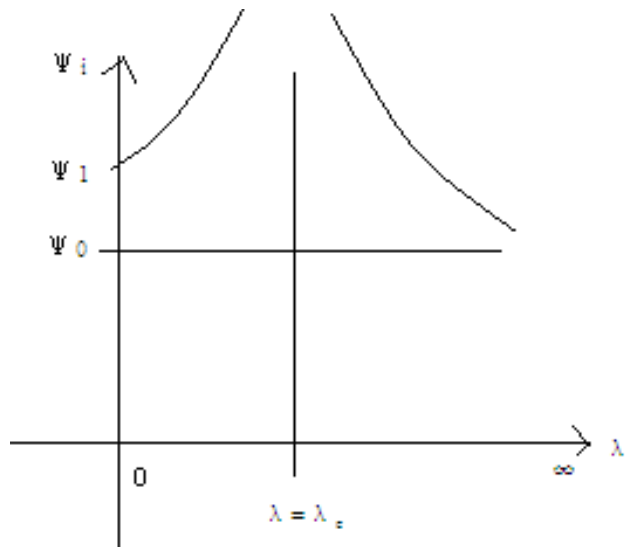

Figure 4. large air volume control rheostat mine economy curve

When the large-scale production meets the $\frac{A}{D}>\frac{K_{1}}{K_{3}}$, the production of large $\psi_{i}-\lambda$ curve is shown in Fig. 4. When the $\lambda=0$ or $\lambda \rightarrow \infty$, that is, only increasing resistance adjustment or just adjust the resistance reduction, economy is relatively low. When $0<\lambda<\infty$, i.e. a joint variable resistance, $\psi_{i}$ with $\lambda$ first increases and then decreases when the $\lambda=K_{1}, \psi_{i} \rightarrow \max$, economy best, so $\lambda_{e}=K_{1}$, this time drag mine changes in the value of total $\Delta R \rightarrow 0$, from the mine drag curve can also be seen, no additional energy consumption, and stable air flow, relative to the scale of production, the proportion of project costs are relatively small, so efficiency is relatively high, consistent with the economic analysis.

So in this production conditions, the joint variable resistance method most superiority, $\lambda$ closer $\lambda_{e}$, mine ventilation system air volume control economy is higher.

The above analysis and reduction in resistance with increasing resistance to the regulation of air flow characteristics match. $\lambda=\lambda_{e}$ time of significance is the change in the value of the mine total drag $\Delta R \rightarrow 0$; mine drag curve does not change; there is no additional energy consumption, ventilation system air flow is stable and rational engineering, economy best.

\section{The main conclusion}

Rheostat for adjusting the mine ventilation system air flow when the mine ventilation system should be considered wind stability [1], the scale of production, energy consumption, and engineering, to choose the best method for regulating the mine ventilation system to ensure safe and economical operation.

Joint variable resistance method is suitable for largescale production of the mine, then you can adjust the resistance reduction and comprehensive adjustment method has the advantage of increasing resistance, variable resistance proportional ratio $\lambda=\lambda_{e}$ variable resistance air volume control has the highest economy.

Increasing resistance mine ventilation system air volume control should be avoided in the mine well into the main, install conditioning return air duct, or affect the air flow stability [1], which indirectly affects economy. Reduction in resistance adjustment should be avoided in the construction of the tunnel with the wind resistance reduction because of the cost of the project, a large, complex operation, and can be reduced slightly, with little success, the economy is poor.

Optimization of mine ventilation system design, as far as possible, pre-designed mine ventilation system network architecture, resistance distribution and air flow with the actual situation and put into operation in line to reduce the daily mine ventilation system regulation times it had to keep the main fan working conditions point for stability, reduce the additional energy consumption and maintenance cost of the project.

\section{Conclusion}

The objective of any ventilation system is twofold. First, the primary ventilation must allow air through the main airways to the immediate working area out by the working faces, thus making fresh air available for face ventilation, and then return the contaminated air through return (exhaust) airways to the surface. Second, the face 
ventilation system must be designed to effectively utilize the available air in the immediate working area to sweep the working face, to capture and remove dust, and to dilute and carry away gas, if any, emitted during mining activities. The Ivory Coast mines need an effective ventilation system to create suitable micro-environment of the working face. Constructing such system provides solution to the heat problems and has profound significance on safety in the mine, thus making the mine activities a good venture.

\section{References}

1. Veiga, M. M., Angeloci, G., Hitch, M., \& VelasquezLopez, P. C.. Processing centres in artisanal gold mining. Journal of Cleaner Production, 64:535-544, (2014).

2. Veiga, M. M., Angeloci, G., Niquen, W., \& Seccatore, J. Reducing mercury pollution by training
Peruvian artisanal gold miners. Journal of Cleaner Production, 94, 268-277, (2015).

3. Veiga, M. M. Introducing new technologies for abatement of global mercury pollution in Latin America . CETEM/CNP, p. 94, (1997).

4. Wang Chong-Xian, LI Xu Guo, Tan waves. Mine ventilation system air volume factors influencing the stability [J]. Coal, 33(8):931-935, (2008).

5. Zhang Guo. Ventilation Safety Science [M]. Xuzhou: China University of Mining Press, (2007).

6. Xurui Long. Ventilation Network Theory [M]. Beijing: Coal Industry Press, (1993).

7. Yhingmin.Mine aerodynamics and mine ventilation system[M].Beijing:Metallurgical Industry Press, (1994).

8. Xie Zhenhua, Song Cun-yi. Engineering fluid mechanics [M]. Beijing: Metallurgical Industry Press, (2007). 